\title{
Correspondence
}

\section{'Tree of life' took root 150 years ago}

As thousands of scientists and policymakers gather in Mexico this month for the COP13 summit on biodiversity (see www. cbd.int/cop2016), we should take a moment to celebrate the earliest 'tree of life' model of biodiversity.

Charles Darwin published the idea of a tree of life in On the Origin of Species in 1859. Seven years later, German zoologist Ernst Haeckel painstakingly drew up a much more comprehensive tree (pictured). This represented Earth's wealth of species in the context of evolution - a concept he dubbed phylogeny (General Morphology of Organisms; 1866).

The root of the tree symbolizes a common primordial ancestor from which all other forms emerged. Haeckel developed his tree over almost 1,000 pages, basing it on palaeontological, embryological and systemic data - a precursor to modern biology's phylogenetic trees.

$\mathrm{He}$ also coined the term ecology ('oecologie'), describing it as "the whole science of the relations of the organism to the environment including, in the broad sense, all the 'conditions of existence'".

Haeckel's ideas were harbingers for discoveries such as that by ecologist Santiago Soliveres and colleagues, who demonstrated that ecosystem multifunctionality depends on high species richness (Nature 536, 456-459; 2016). Uwe Hossfeld, Georgy S. Levit Friedrich Schiller University, Jena, Germany; and ITMO University, St Petersburg, Russia. gslevit@corp.ifmo.ru

\section{Conservation: smart advocacy needs data}

We agree that data alone will not save species (A. M. Ellison Nature 538, 141; 2016). However, using data in combination with smart advocacy can make a difference.

For example, ecologists

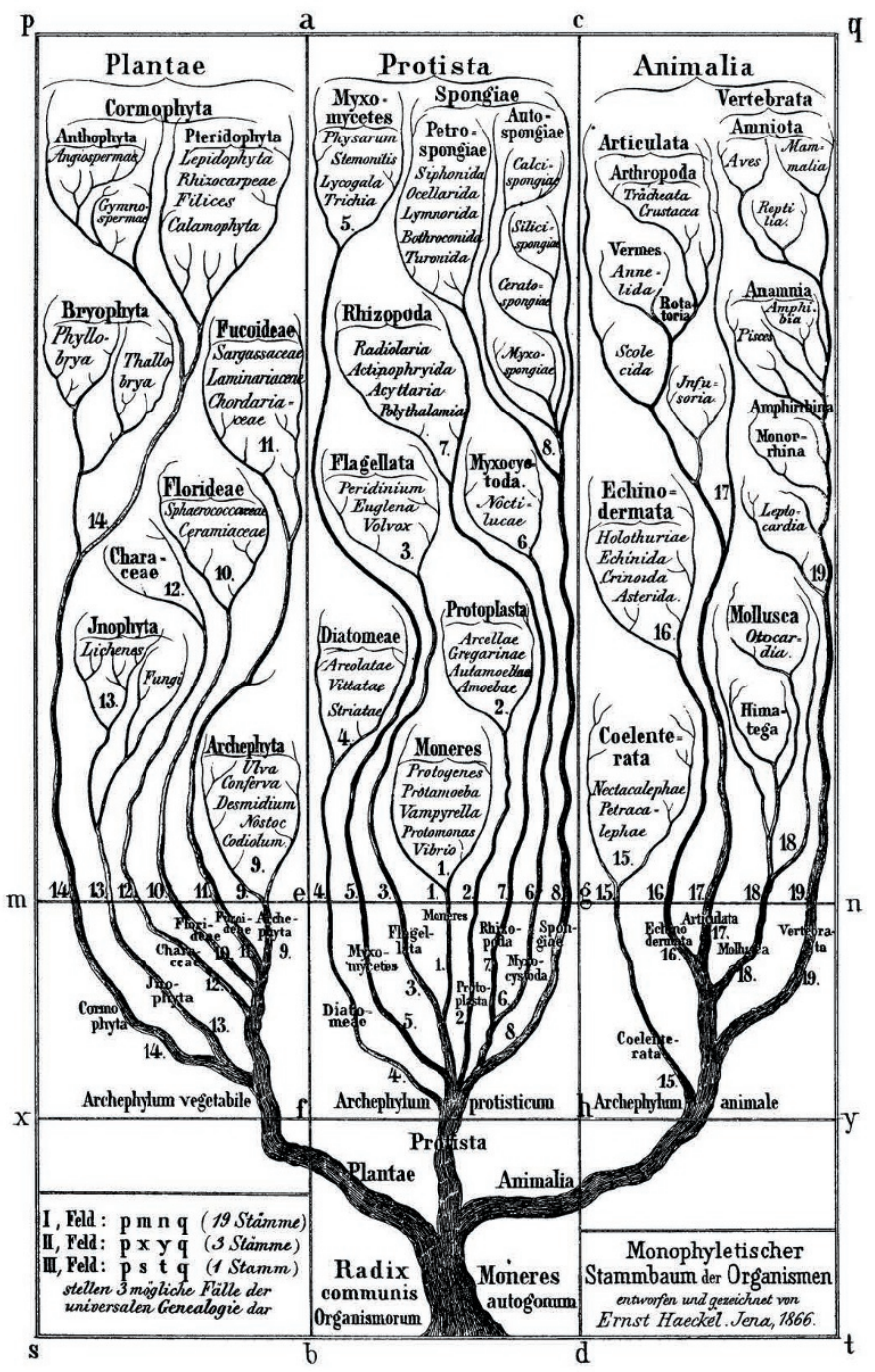

specializing in seabirds, fishes and coral reefs shared their data to show that protection of an area in the northwest Hawaiian Islands was scientifically justified. This evidence was required in order to use the US Antiquities Act to conserve the region. As a result, this became the world's largest no-take protected area earlier this year.

Contrary to Aaron Ellison's implication, some ecologists have been inspirational advocates for biodiversity. For example, biologist E. O. Wilson campaigns to protect half the planet (Half-

Earth; Norton, 2016) and ecologist Daniel Janzen helped to save huge tracts of dry forest in Costa Rica (W. Allen Green Phoenix; Oxford Univ. Press, 2003).
More scientists need to be engaged with society and make the case for conservation with good, compelling data in hand. None of us wants our publications to serve as pages in a wildlife obituary.

Douglas J. McCauley, Francis

H. Joyce University of California, Santa Barbara, USA.

Jane Lubchenco Oregon State University, Corvallis, Oregon, USA. dmccauley@ucsb.edu

\section{Conservation: big data boost in China}

I disagree with Aaron Ellison's contention that biodiversity data only rarely drive conservation decisions (Nature 538, 141; 2016).
In China, better data are guiding changes in conservation policies and on-the-ground actions.

For instance, huge long-term data sets on species, ecosystems and human activities have enabled China to identify many priority conservation areas for protecting biodiversity and maintaining ecological security (R. Wu et al. PLoS ONE 9, e103783; 2014). Intensive development is prohibited in these areas.

Furthermore, a huge amount of data from hundreds of scientists are used by China's Ministry of Environmental Protection to compile biodiversity 'red lists' (R. Wu Science 353, 657; 2016). And the systematic collection of more and better data is crucial to implementation of the government's nationwide 'Red Lines', which demarcate ecological conservation regions (see W. Sang and J.C. Axmacher Nature 531, 305; 2016).

Ruidong Wu Yunnan University, Kunming, Yunnan, China. rdwu@ynu.edu.cn

\section{Conservation: thrive on slings and arrows}

Aaron Ellison rightly calls for conservation scientists to engage more actively in the political process (Nature 538, 141; 2016). Unfortunately, those doing so can become targets for physical and verbal threats, personal abuse, bullying and trolling on social media.

As a conservation scientist, I have experienced many such reactions at first hand. I have been embroiled for more than 30 years in the politics of native forest logging, tree-plantation expansion and culling of overabundant native and exotic animals. Resilience against such attacks is underpinned by a drive to conduct and communicate high-quality science that contributes to the conservation and management of natural environments and biodiversity.

Communicating good data 